\title{
RESEARCH ON Cr${ }^{6+}$ ADSORPTION OF MODIFIED CARBONIZED STRAW AND ITS MECHANISM DURING WASTEWATER TREATMENT BY RESPONSE SURFACE METHODOLOGY
}

\author{
ZENG, Y.G. ${ }^{1 *}-$ LI, W.Y. ${ }^{1}-$ LUO, L. ${ }^{2}-$ DU, T.T. ${ }^{3}-$ YANG, P. ${ }^{1}-$ XU, Q. ${ }^{1}-$ LIU, J.J. ${ }^{4}-$ SHEN, J.W. \\ - ZENG, Y. ${ }^{1}-\mathrm{LI}, \mathrm{X} .{ }^{1}-\mathrm{CHEN}, \mathrm{X} . X .^{1}-\mathrm{JIA}, \mathrm{R} . \mathrm{X} .^{1}$ \\ ${ }^{1}$ School of Architecture and Civil Engineering, Chengdu University, Chengdu 610106, China \\ ${ }^{2}$ Post Office in Chengdu, Sichuan Province, Chengdu 610011, China \\ ${ }^{3}$ School of Environment, Harbin Institute of Technology, Shenzhen 518055, China \\ ${ }^{4}$ School of Mechanical Engineering, Chengdu University, Chengdu 610106, China \\ *Corresponding author \\ e-mail:122054216@qq.com
}

(Received 22 ${ }^{\text {nd }}$ May 2019; accepted $28^{\text {th }}$ Aug 2019)

\begin{abstract}
Heavy metal contaminated wastewater is difficult to treat, and trace amounts of heavy metals can produce toxic effects. In order to provide a more reliable basis for controlling heavy metal pollution, modified carbonized straw was used to adsorb $\mathrm{Cr}^{6+}$ in this study, and the optimal adsorption conditions and adsorption effects of $\mathrm{Cr}^{6+}$ were studied. Finally, the adsorption kinetics and adsorption activation thermodynamics were analyzed and studied. The results showed that the iodine adsorption value of carbonized wheat straw modified using $\mathrm{FeCl}_{2}$ activation method was the highest at $1161.15 \mathrm{mg} / \mathrm{g}$. The response surface method can be used to optimize the adsorption conditions of $\mathrm{Cr}^{6+}$ adsorbed by modified carbonized straw and predict the optimal conditions for $\mathrm{Cr}^{6+}$ adsorption. Experiments showed that the actual value was in agreement with the predicted value, indicating that the response surface methodology was feasible to optimize the adsorption of $\mathrm{Cr}^{6+}$ by modified carbonized straw. In the kinetic analysis, the Elovich equation could better describe the adsorption of $\mathrm{Cr}^{6+}$ by modified carbonized wheat straw, and its fitting degree exceeded 0.91 . In the analysis of thermodynamic parameters, $\Delta H>0, \Delta \mathrm{G}<0$, indicating that the adsorption of $\mathrm{Cr}^{6+}$ by modified wheat straw was a spontaneous endothermic process. During the adsorption process, $\Delta \mathrm{S}>0$, indicating that the adsorption of $\mathrm{Cr}^{6+}$ by modified carbonized wheat straw increased the disorder of the system.
\end{abstract}

Keywords: modified carbonization straw, $\mathrm{Cr}^{6+}$, response surface methodology, adsorption kinetics, heavy metal wastewater, heavy metal wastewater treatment, iodine adsorption value, agricultural waste

\section{Introduction}

With the development of industry in China, heavy metal pollution has seriously endangered human health. In fact, heavy metal pollution is difficult to be degraded and removed by simple methods, and it tends to accumulate in organisms and produce toxic effects (Zhao, 2016). At present, the aggravation of heavy metal pollution poses a great threat to the healthy development of human beings and other organisms, and the treatment of heavy metal wastewater has become an urgent problem to be solved. Therefore, it is of great significance to analyze and study the treatment and disposal of heavy metal wastewater (Zeng, 2014a; Zeng and Li, 2014b).

China is a country of traditional agricultural production (Cao et al., 2012). At present, China's agricultural straw production is high. However, with the improvement of people's living standards, straw is no longer needed in daily life. Nowadays, most of 
the straw is treated by incineration and disposal, and has not been reused (Sud et al., 2008), which not only wastes resources, but also brings more and more serious air pollution problems. Therefore, a large number of agricultural straws have not been properly utilized, and the conventional disposal methods have been unable to meet the current straw disposal requirements. In response to the call for building a resourceconserving and environment-friendly society, reusing these residues to dispose of waste is a good way to deal with agricultural waste (Ngah and Hanafiah, 2008). Straw is a biomass waste with high crude fiber content and low protein content (Zhu et al., 2010), which is difficult to be corroded, and it is not good to be directly returned to the field. However, the carbonized product of straw has good physicochemical properties, such as good combustibility, adsorption and low electrical resistance (Sun and Jiang, 2009), which can be used as fuels, soil conditioners and filling materials for electromagnetic shielding screen. Therefore, it is a feasible path to improve the comprehensive utilization rate of straw and carry out biochar utilization of straw and other biomass.

On the basis of the previous studies (Zeng et al., 2018), wheat, corn and paddy straw from farmland around Chengdu, Sichuan Province were carbonized to produce carbonized straw, which is used as activated carbon to study the best adsorption conditions and effects for $\mathrm{Cr}^{6+}$, and the adsorption kinetics and thermodynamics of adsorption activation state were studied finally. In addition, this study evaluated the treatment of $\mathrm{Cr}^{6+}$ by modified carbonized straw, which is expected to provide some technical and theoretical support for the practical application of this method.

\section{Materials and methods}

\section{Materials, reagents and instruments}

The materials used in this experiment were waste wheat, corn, and rice straw produced by agriculture. Corn stalks were taken from Xihe Town, Longquanyi, Chengdu. Wheat straw and rice straw were taken from Huayang Town, Shuangliu, Chengdu.

The object of this experiment was a solution containing $\mathrm{Cr}^{6+}$. The reagents used in the experiment were $\mathrm{ZnCl}_{2}, \mathrm{KOH}, \mathrm{HCl}, \mathrm{HNO}_{3}, \mathrm{H}_{2} \mathrm{SO}_{4}, \mathrm{~K}_{2} \mathrm{Cr}_{2} \mathrm{O}_{7}, \mathrm{FeCl}_{2}, \mathrm{I}_{2}, \mathrm{KI}$, $\mathrm{Na}_{2} \mathrm{~S}_{2} \mathrm{O}_{3}$, soluble starch. All reagents were analytical pure. The equipments of the experiment include electrothermal constant temperature blast drying oven (DHG9140A), visible light spectrophotometer (V-1200), water bath oscillator (HH-4), electronic analytical balance (ESJ120-4), $\mathrm{pH}$ meter (PHS-3C), constant temperature oscillator (THZ-032), electric stirrer (JJ-1), ultrasound instrument (KQ-50), high speed centrifuge (H1650R), universal electric furnace (BDW1-6), mesh screen (40 to 200 mesh).

\section{Preparation of modified carbonized straw}

In this paper, wheat, corn and rice straw were used as raw materials to prepare activated carbon by using chemical activation method, and the activator were zinc chloride, potassium hydroxide, concentrated sulfuric acid and ferrous chloride, the experimental scheme is shown in Table $1(\mathrm{Nu}$ et al., 2017). First, distilled water was applied to clean three kinds of straws. Then straws were dried under the condition of $100{ }^{\circ} \mathrm{C}$ in the electrothermal constant temperature blast drying oven and cut into long strips of 3-4 cm. Next, the dried material was sealed with a foil paper and placed on a 
universal electric furnace for $30 \mathrm{~min}$ (the temperature of wheat straw was $800{ }^{\circ} \mathrm{C}$ (Xiao et al., 2010), the temperature of corn straw was $600^{\circ} \mathrm{C}$ (Chen et al., 2010), and the temperature of rice straw was $300{ }^{\circ} \mathrm{C}$ (Pinto et al., 2005), then the outer wrapped tin foil paper was removed, and the crude carbonized straw obtained after activation was ground and sieved (40 to 60 mesh). Next, the three sieved carbonized straws were mixed with $\mathrm{ZnCl}_{2}(3 \mathrm{~mol} / \mathrm{L}), \mathrm{KOH}(3 \mathrm{~mol} / \mathrm{L}), \mathrm{H}_{2} \mathrm{SO}_{4}(37 \%)$ and $\mathrm{FeCl}_{2}(2 \mathrm{~mol} / \mathrm{L})$ in a mass ratio of $1: 3$ in a $100 \mathrm{~mL}$ stoppered conical flask and closed it immediately, and then it was oscillated in the constant temperature oscillator (temperature: $25{ }^{\circ} \mathrm{C}$, oscillation speed: $150 \mathrm{r} / \mathrm{min}$, oscillation time: $120 \mathrm{~min}$ ). At the end of the oscillation, solid modified carbonized straw was obtained by filtering the mixed liquor. Firstly, it was washed by 1:9 dilute hydrochloric acid solution $(1 \mathrm{~mol} / \mathrm{L})$. Secondly, it was washed repeatedly with distilled water to neutral. Thirdly, it was dried to constant weight. After grinding, the activated carbon in 200-mesh was selected for use.

Table 1. Experimental design of carbonized straw modification

\begin{tabular}{c|c|c|c|c|c|c}
\hline Number & Straw & Activator & $\begin{array}{c}\text { Mass ratio } \\
(\mathbf{g}: \mathbf{m L})\end{array}$ & $\begin{array}{c}\text { Temperature } \\
\left({ }^{\circ} \mathbf{C}\right)\end{array}$ & $\begin{array}{c}\text { Oscillation speed } \\
(\mathbf{r} / \mathbf{m i n})\end{array}$ & $\begin{array}{c}\text { Oscillation time } \\
(\mathbf{m i n})\end{array}$ \\
\hline 1 & Wheat & $\mathrm{ZnCl}_{2}$ & $1: 3$ & 25 & 150 & 120 \\
2 & Wheat & $\mathrm{KOH}$ & $1: 3$ & 25 & 150 & 120 \\
3 & Wheat & $\mathrm{H}_{2} \mathrm{SO}_{4}$ & $1: 3$ & 25 & 150 & 120 \\
4 & Wheat & $\mathrm{FeCl}_{2}$ & $1: 3$ & 25 & 150 & 120 \\
5 & Corn & $\mathrm{ZnCl}_{2}$ & $1: 3$ & 25 & 150 & 120 \\
6 & Corn & $\mathrm{KOH}_{2}$ & $1: 3$ & 25 & 150 & 120 \\
7 & Corn & $\mathrm{H}_{2} \mathrm{SO}_{4}$ & $1: 3$ & 25 & 150 & 120 \\
8 & Corn & $\mathrm{FeCl}_{2}$ & $1: 3$ & 25 & 150 & 120 \\
9 & Rice & $\mathrm{ZnCl}_{2}$ & $1: 3$ & 25 & 150 & 120 \\
10 & Rice & $\mathrm{KOH}_{1}$ & $1: 3$ & 25 & 150 & 120 \\
11 & Rice & $\mathrm{H}_{2} \mathrm{SO}_{4}$ & $1: 3$ & 25 & 150 & 120 \\
12 & Rice & $\mathrm{FeCl}_{2}$ & $1: 3$ & 25 & 150 & 120 \\
\hline
\end{tabular}

\section{Method for determining iodine value of modified carbonized straw}

The iodine level is related to the adsorption capacity of activated carbon. It is generally believed that the higher the iodine value, the higher the porosity of activated carbon, which means the high adsorption capacity. In this experiment, the iodine value of modified carbonized straw was determined by national standard GB/T12496.8-2015 "Determination of iodine adsorption value by wood activated carbon experimental method" (Chen et al., 2007).

\section{Drawing method of standard curve of $\mathrm{Cr}^{6+}$}

A certain concentration of $\mathrm{Cr}^{6+}$-containing solution was configured with distilled water as a reference, and absorbance was measured at its maximum absorption wavelength (each sample was measured three times, averaged and recorded, $n=3$ ). Taking $540 \mathrm{~nm}$ as the maximum absorption wavelength of $\mathrm{Cr}^{6+}$, the concentration of the $\mathrm{Cr}^{6+}$-containing solution respectively was $0 \mathrm{mg} / \mathrm{L}, 0.02 \mathrm{mg} / \mathrm{L}, 0.1 \mathrm{mg} / \mathrm{L}, 0.4 \mathrm{mg} / \mathrm{L}$, and $0.8 \mathrm{mg} / \mathrm{L}$. Then, the experiment was performed, the measured absorbance was taken as the ordinate, the concentration was taken as the abscissa, and the standard curve was drawn. 


\section{Configuration of $\mathrm{Cr}^{6+}$-containing solution}

First, the best grade pure potassium dichromate was weighed $1.4135 \mathrm{~g}$ and dissolved in water, and then the volume of solution reached at $500 \mathrm{~mL}$ by adding water. Therefore, the standard reserve solution containing $\mathrm{Cr}^{6+} 1.0 \mathrm{mg} / \mathrm{mL}$ was obtained. When the solution needs to be used, the standard reserve solution is absorbed with $1.0 \mathrm{~mL}$ nitric acid, and then a standard solution containing $100 \mathrm{mg} / \mathrm{mL} \mathrm{Cr}^{6+}$ was obtained (Chen et al., 2010).

\section{Response surface experiment of $\mathrm{Cr}^{6+}$}

The experiment used the Box-Behnken design to predict the optimal adsorption conditions and explore the interaction between the factors through Design Expert software (Hadjmohammadi et al., 2016). In this experiment, temperature (A), adsorption time (B), and adsorbent dosage (C) were used as independent variables, the removal rate of $\mathrm{Cr}^{6+}$ by activated carbon modified under different conditions as a response value, and then the adsorption performance of modified carbonized straw for adsorption of $\mathrm{Cr}^{6+}$ was optimized. The experimental design was shown in Table 4.

\section{Adsorption kinetics}

In this study, the first-order kinetic equation, the double-constant equation, and the Elovich equation were used to analyze the adsorption kinetics of the $\mathrm{Cr}^{6+}$-containing solution by modified carbonized straw.

The linear expression of the first-order kinetic equation is as follows Equation 1 (Takeshi et al., 2004). In the formula, $C_{t}$ is the mass concentration at time $t(\mathrm{mg} / \mathrm{L})$, a and $\mathrm{k}$ are the kinetic constants, $\mathrm{t}$ is the adsorption time.

$$
\ln C_{t}=\mathrm{a}-\mathrm{kt}
$$

The double-constant equation is suitable for complex non-homogeneous diffusion processes, and the linear expression of which is as follows (Eq. 2) (Wu, 2015). In the formula, $\mathrm{X}$ is adsorption capacity $(\mathrm{mg} / \mathrm{g})$, a and $\mathrm{k}$ are the kinetic constants, $\mathrm{t}$ is the adsorption time.

$$
\ln X=a+k \ln t
$$

The linear expression of the Elovich equation (Shi and Li, 2014) is as follows (Eq. 3). In the formula, $X$ is adsorption capacity $(\mathrm{mg} / \mathrm{g})$, a and $\mathrm{k}$ are the kinetic constants, $\mathrm{t}$ is the adsorption time.

$$
X=a+k \operatorname{lnt}
$$

\section{Adsorption thermodynamics}

Calculating the change of standard thermodynamic function based on experimental data of adsorption thermodynamics is an important part of adsorption thermodynamics research, which has theoretical and practical significance (McKay, 1984). In the adsorption process, the relationships between the thermodynamic functions $\Delta \mathrm{G}, \Delta \mathrm{H}, \Delta \mathrm{S}$ and the adsorption partition coefficient $\mathrm{K}$ are as follows (Eqs. 4-7). 


$$
\begin{gathered}
K=\frac{q_{e}}{C_{e}} \\
\Delta G=-R T \ln K \\
\Delta G=\Delta H-\mathrm{T} \Delta S
\end{gathered}
$$

From the above formulas:

$$
\ln K=\frac{\Delta S}{R}-\frac{\Delta H}{R T}
$$

In the formulas, $\mathrm{q}_{\mathrm{e}}$ is the equilibrium adsorption amount $(\mathrm{mg} / \mathrm{g}), \mathrm{C}_{\mathrm{e}}$ is the mass concentration of adsorbate in solution during adsorption equilibrium $(\mathrm{mg} / \mathrm{L}), \mathrm{T}$ is the thermodynamic temperature $(\mathrm{K}), \mathrm{R}$ is the gas constant $(8.314 \mathrm{~J} /(\mathrm{mol} \cdot \mathrm{k})), \mathrm{K}$ is the adsorption partition coefficient, $\Delta \mathrm{H}$ is the change of adsorption enthalpy $(\mathrm{kJ} / \mathrm{mol}), \Delta \mathrm{S}$ is the change of adsorption entropy $(\mathrm{J} /(\mathrm{mol} \mathrm{K})), \Delta \mathrm{G}$ is adsorption free energy $(\mathrm{kJ} / \mathrm{mol})$.

\section{Experimental results and analysis}

\section{Results of modified carbonized straw}

The straw obtained after carbonization was dark black, and it had a brittle texture and was lighter in weight than raw materials. The activated carbonized straw was black powder after drying and grinding, and the straw components were shown in Table 2.

Table 2. Component of straw

\begin{tabular}{c|c|c|c|c}
\hline Straw & Lignin & Crude fiber & Crude ash & Crude protein \\
\hline Rice & $6.3 \%$ & $35.1 \%$ & $19.4 \%$ & $3.2 \%$ \\
Corn & $4.6 \%$ & $29.3 \%$ & $7.0 \%$ & $9.3 \%$ \\
Wheat & $9.5 \%$ & $43.6 \%$ & $2.6 \%$ & $2.6 \%$ \\
\hline
\end{tabular}

It could be seen from Table 2 that the lignin content and crude fiber content of wheat straw were higher than those of rice straw and corn straw, and the pore structure of cellulose directly affected subsequent adsorption properties.

In the process of carbonization and modification, the average pore size of straw decreased, which made the total pore volume increase. At the same time, the nonmicrocrystalline carbon of the carbon structure was oxidized, which made the specific surface area larger, and the microcrystalline carbon was rearranged to make pores more stable. Therefore, the specific surface area of the modified carbonized straw was much higher than the specific surface area of the original straw. In fact, the increase in specific surface area increased the adsorption area of the adsorbent for heavy metals, and then the adsorption rate was increased (Zhong, 2011).

During the adsorption process, with the increase of temperature, raw materials were rapidly decomposed by heat, so $\mathrm{C}-\mathrm{OH}, \mathrm{C}-\mathrm{O}-\mathrm{C}, \mathrm{C}-\mathrm{H}$ and other groups in cellulose molecular structure were decomposed at $280 \sim 380{ }^{\circ} \mathrm{C}$, and small amount of molecule fragments or groups were decomposed continuously when the temperature more than 


$$
-12990 \text { - }
$$

$380^{\circ} \mathrm{C}$. At the same time, carbon element was rearranged to form graphite microcrystalline (Zhu and Zhou, 2014).

\section{Determination and analysis of iodine value of modified carbonized straw}

Through the measurement experiment of iodine value, the iodine values of the experimental samples were shown in Table 3.

Table 3. Iodine value of different modified carbonized straw

\begin{tabular}{c|c|c|c}
\hline Number & Carbonized straw & Modifier & Iodine value (mg/g) \\
\hline 1 & Wheat & $\mathrm{ZnCl}_{2}$ & 1005.32 \\
2 & Wheat & $\mathrm{KOH}$ & 993.84 \\
3 & Wheat & $\mathrm{H}_{2} \mathrm{SO}_{4}$ & 994.86 \\
4 & Wheat & $\mathrm{FeCl}_{2}$ & 1161.15 \\
5 & Corn & $\mathrm{ZnCl}_{2}$ & 1072.23 \\
6 & Corn & $\mathrm{KOH}$ & 1135.19 \\
7 & Corn & $\mathrm{H}_{2} \mathrm{SO}_{4}$ & 1101.27 \\
8 & Corn & $\mathrm{FeCl}_{2}$ & 962.80 \\
9 & Rice & $\mathrm{ZnCl}_{2}$ & 1021.13 \\
10 & Rice & $\mathrm{KOH}$ & 993.87 \\
11 & Rice & $\mathrm{H}_{2} \mathrm{SO}_{4}$ & 937.04 \\
12 & Rice & $\mathrm{FeCl}_{2}$ & 1007.25 \\
\hline
\end{tabular}

In this study, different carbonized straws were modified by different modifiers, and the iodine adsorption value was used as an indicator to compare the adsorption capacity of different modified carbonized straws. After the four modifiers were applied separately, the adsorption capacity of the modified wheat straw was greater than that of corn and rice straw, which might be closely related to the content of crude fiber and lignin in wheat straw. In the experiment, the modified carbonized wheat straw with $2 \mathrm{~mol} / \mathrm{L} \mathrm{FeCl}_{2}$ as modifier had the highest iodine adsorption value $1161.15 \mathrm{mg} / \mathrm{g}$. Therefore, the subsequent adsorption experiments selected modified carbonized wheat straw as the main research object, which used $2 \mathrm{~mol} / \mathrm{L} \mathrm{FeCl}_{2}$ as modifier.

\section{Response surface analysis of $\mathrm{Cr}^{6+}$}

Based on single factor experiments and orthogonal experiments, this study used Design Expert software to design a response surface experimental scheme in BoxBehnken mode, and then used model analysis to predict the optimal adsorption conditions and the interaction between the factors. In the experiments, temperature (A), adsorption time (B), and dosage of adsorbent (C) were used as independent variables, and the removal rate of $\mathrm{Cr}^{6+}$ by activated carbon was used as the response value, and then the adsorption conditions for the adsorption of $\mathrm{Cr}^{6+}$ by modified carbonized straw were optimized. The experimental results were shown in Table 4.

The results of the Table 4 were analyzed and modeled, and then the quadratic polynomial regression equations of temperature (A), adsorption time (B), adsorbent dosage $(\mathrm{C})$, and $\mathrm{Cr}^{6+}$ adsorption rate $\mathrm{R}$ were obtained as follows $(E q .8)$ :

$$
R=98.20+1.66 \mathrm{~A}+0.57 \mathrm{~B}+0.51 \mathrm{C}-0.010 \mathrm{AB}+0.23 \mathrm{AC}+0.22 \mathrm{BC}-1.81 \mathrm{~A}^{2}-0.69 \mathrm{~B}^{2}-0.42 \mathrm{C}^{2}(\mathrm{Eq} .8)
$$


Table 4. Results of response surface experiments

\begin{tabular}{c|c|c|c|c}
\hline \multirow{2}{*}{ Number } & \multicolumn{3}{|c|}{ Condition } & Response value-removal \\
& Temperature A $\left({ }^{\circ} \mathbf{C}\right)$ & Time B (h) & Dosage C $(\mathbf{g})$ & $\begin{array}{c}\text { rate } \\
\text { ryyn}\end{array}$ \\
\hline 1 & 25 & 2.5 & 2.4 & 98.17 \\
2 & 25 & 2.5 & 2.4 & 98.45 \\
3 & 35 & 3.5 & 2.4 & 98.28 \\
4 & 25 & 3.5 & 3.6 & 94.18 \\
5 & 15 & 3.5 & 2.4 & 95.16 \\
6 & 15 & 2.5 & 3.6 & 98.12 \\
7 & 25 & 2.5 & 2.4 & 98.68 \\
8 & 25 & 2.5 & 2.4 & 98.14 \\
9 & 35 & 2.5 & 3.6 & 93.09 \\
10 & 15 & 1.5 & 2.4 & 97.14 \\
11 & 25 & 3.5 & 1.2 & 97.23 \\
12 & 35 & 1.5 & 2.4 & 96.38 \\
13 & 25 & 1.5 & 1.2 & 97.88 \\
14 & 25 & 2.5 & 2.4 & 96.31 \\
15 & 35 & 2.5 & 1.2 & 94.24 \\
16 & 15 & 2.5 & 1.2 & 96.53 \\
17 & 25 & 1.5 & 3.6 & \\
\hline
\end{tabular}

The quadratic polynomial model and the results of various variance analyses were shown in Table 5, which could be used to judge the adaptability of the model to the study and lay the foundation for subsequent research.

Table 5. Variance analysis of the model

\begin{tabular}{c|c|c|c|c|c|c}
\hline Resource & $\begin{array}{c}\text { Quadratic } \\
\text { sum }\end{array}$ & $\begin{array}{c}\text { Degree of } \\
\text { freedom }\end{array}$ & $\begin{array}{c}\text { Mean } \\
\text { square }\end{array}$ & F value & Prob > F & Significance \\
\hline Model & 44.91 & 9 & 4.99 & 18.48 & 0.0004 & $* *$ \\
A-temperature & 22.08 & 1 & 22.08 & 81.76 & $<0.0001$ & $* *$ \\
B-time & 2.59 & 1 & 2.59 & 9.58 & 0.0174 & $*$ \\
C-dosage & 2.04 & 1 & 2.04 & 7.56 & 0.0286 & $*$ \\
AB & 1.31 & 1 & 1.31 & 0.86 & 0.9704 & Not significant \\
AC & 0.21 & 1 & 0.21 & 0.77 & 0.4103 & Not significant \\
BC & 0.20 & 1 & 0.20 & 0.73 & 0.4201 & Not significant \\
$A^{2}$ & 13.83 & 1 & 113.83 & 51.23 & 0.0002 & $* *$ \\
$B^{2}$ & 2.02 & 1 & 2.02 & 7.48 & 0.0291 & $*$ \\
$C^{2}$ & 0.76 & 1 & 0.76 & 2.82 & 0.1372 & Not significant \\
Residual & 1.89 & 7 & 0.27 & & & \\
Unfitting term & 1.55 & 3 & 0.52 & 6.02 & 0.0577 & Not significant \\
Pure error & 0.34 & 4 & 0.086 & & & \\
Total deviation & 46.80 & 16 & & & & \\
$R^{2}$ & 0.9596 & Adj $R^{2}$ & 0.9077 & $C V$ & $0.54 \%$ & \\
Precision & 12.354 & & & & & \\
\hline
\end{tabular}

*Significant $(\mathrm{P}<0.05), * *$ highly significant $(\mathrm{P}<0.01)$ 
According to the Table 5, the $\mathrm{P}$ value of the model was 0.0004 , and the unfitting term was 0.0577 , which indicated that the model was not significant, but the regression was significant. The correlation coefficient (R2) was 0.9596, indicated that the fitting effect was better; the variation coefficient was $0.54 \%$, indicated that the model had good reliability and accuracy. The precision indicated the ratio of signal to noise, which should normally be greater than 4 . The precision of this experiment was 12.354 , indicated that the model could appropriately reflect the experimental results (Han et al., 2018). In addition, correlation coefficient $\left(\mathrm{R}^{2}\right)$ and correction correlation coefficient (Adj $\mathrm{R}^{2}$ ) showed that the fitting degree and correlation of the model were high, which indicated that the model could be used to predict the optimal adsorption conditions of $\mathrm{Cr}^{6+}$ on modified carbonized straw.

\section{Effect of temperature and time on the adsorption rate of $\mathrm{Cr}^{6+}$}

In Figure 1, the left graph was a three-dimensional model of temperature, time, and chromium ion adsorption rate, and the right graph was the equal adsorption rate line for adsorption time and temperature. The shape of the equal adsorption rate line could reflect the strength of the interaction of the investigation factors. If it was circular, it meant that the interaction effect was not significant. However, if it was elliptical, it meant that the interaction effect was significant (Pang et al., 2017).
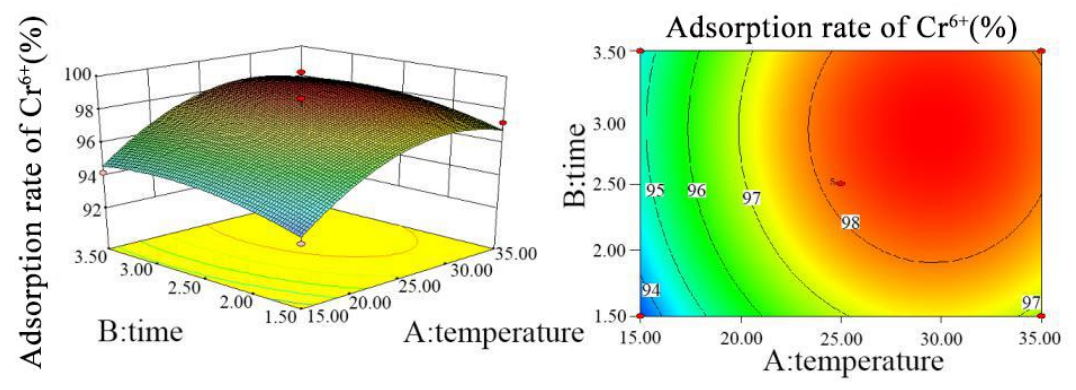

Figrue1. Effect of temperature and time on the adsorption rate of $\mathrm{Cr}^{6+}$

As shown in Figure 1, the adsorption rate increased with the increase of temperature, indicated that heating was beneficial to the adsorption reaction. In addition, when the treatment time increased from 1.5 to $3.5 \mathrm{~h}$, the adsorption rate increased first and then tended to be slow, indicated that the modified carbonized straw adsorbed $\mathrm{Cr}^{6+}$ rapidly first and then gradually reached adsorption equilibrium. According to Table 5, the $\mathrm{P}$ value of temperature $(\mathrm{A})$ was $<0.0001$, the $\mathrm{P}$ value of time $(\mathrm{B})$ was 0.0174 , and the $\mathrm{P}$ value of $\mathrm{AB}$ was $0.9704>0.05$, indicated that the influence of factors $\mathrm{A}$ and $\mathrm{B}$ on the adsorption rate of $\mathrm{Cr}^{6+}$ had no interaction. According to the multiple quadratic regression equation obtained from the response surface, the coefficient of $\mathrm{AB}$ was -0.010 , indicated that the interaction of the two factors had a negative effect on the result.

\section{Effect of temperature and dosage on the adsorption rate of $\mathrm{Cr}^{6+}$}

As shown in Figure 2, the adsorption rate increased with increasing temperature, and a high adsorption rate could be achieved at $25^{\circ} \mathrm{C}$. And then the temperature continued to increase, but the adsorption rate increased slowly. Under the condition of constant temperature, the adsorption rate increased with the increase of dosage. However, when 
the dosage reached $2.4 \mathrm{~g}$, the adsorption rate increased very slowly. According to Table 5, the $\mathrm{P}$ value of temperature $(\mathrm{A})$ was $<0.0001$, the $\mathrm{P}$ value of dosage $(\mathrm{C})$ was 0.0286 , and the $\mathrm{P}$ value of $\mathrm{AB}$ was $0.4103>0.05$, indicated that the influence of factors $\mathrm{A}$ and $\mathrm{C}$ on the adsorption rate of $\mathrm{Cr}^{6+}$ had no interaction. According to the multiple quadratic regression equation obtained from the response surface, the coefficient of $\mathrm{AC}$ was +0.23 , indicated that the interaction of the two factors had a positive effect on the result.
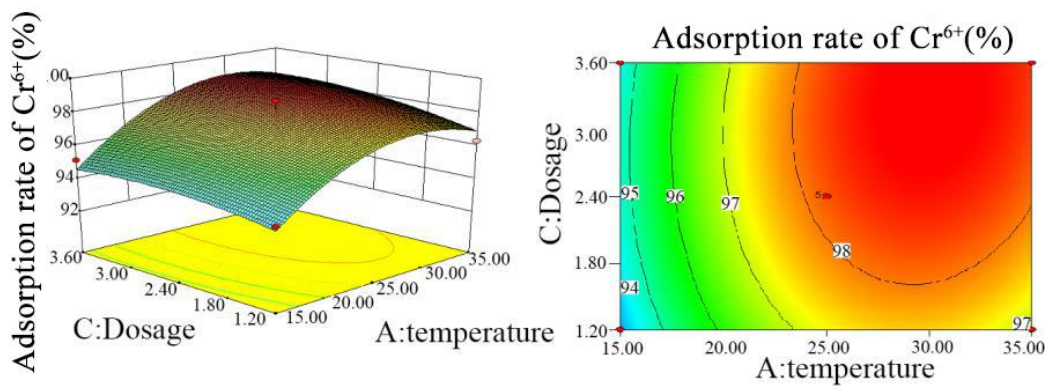

Figure 2. Effect of temperature and dosage on the adsorption rate of $\mathrm{Cr}^{6+}$

\section{The effect of time and dosage on the adsorption rate of $\mathrm{Cr}^{6+}$}

It could be seen from Figure 3 that when the time was constant, the adsorption rate increased with the increase of the dosage, but when the dosage exceeded $2.4 \mathrm{~g} / \mathrm{L}$, the increase rate of the adsorption rate gradually decreased. At the same time, when the dosage was constant, the adsorption rate also increased with the time, and the growth rate was low. Theoretically, that was because the adsorbent rapidly adsorbed $\mathrm{Cr}^{6+}$ in the initial stage and had reached saturation in the later stage, so the adsorption rate did not increase significantly in the later stage. According to Table 5, the $\mathrm{P}$ value of time (B) was 0.0174 , the $\mathrm{P}$ value of dosage $(\mathrm{C})$ was 0.0286 , and the $\mathrm{P}$ value of $\mathrm{BC}$ was $0.4201>0.05$, indicated that the influence of factors $\mathrm{B}$ and $\mathrm{C}$ on the adsorption rate of $\mathrm{Cr}^{6+}$ had no interaction. According to the multiple quadratic regression equation obtained from the response surface, the coefficient of $\mathrm{BC}$ was +0.22 , indicated that the interaction of the two factors had a positive effect on the result.
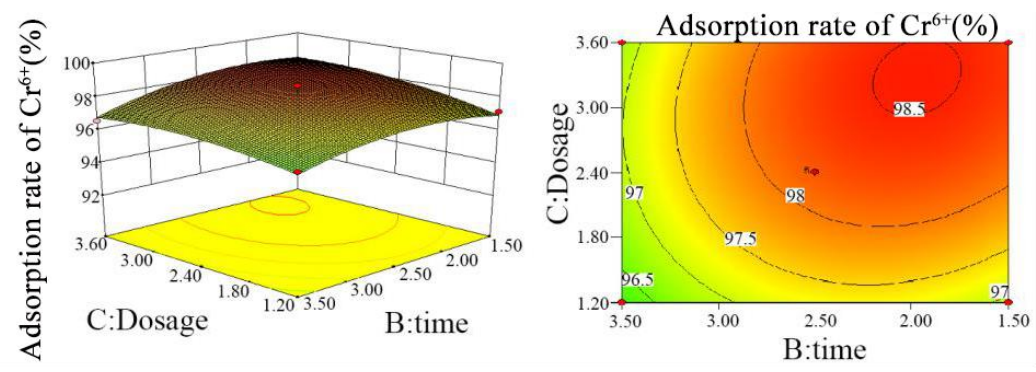

Figure 3. Effect of time and dosage on the adsorption rate of $\mathrm{Cr}^{6+}$

The optimal solution was selected by response surface analysis

Further analysis was performed using the fitted multiple quadratic regression equation and Design-Expert 8.0.6 software. And the predicted values of the optimal values and optimal processing conditions were obtained within the experimental design 
conditions. The optimal conditions for prediction were as follows: when the temperature was $30.12{ }^{\circ} \mathrm{C}$, time was $3.05 \mathrm{~h}$, the dosage was $3.45 \mathrm{~g}$, the modified carbonized straw had the best adsorption effect on $\mathrm{Cr}^{6+}$. And then it was proved that the actual and predicted values were well fitted, which indicated that it was feasible to optimize the modified carbonized straw to absorb $\mathrm{Cr}^{6+}$ by response surface method.

\section{Adsorption kinetics of $\mathrm{Cr}^{6+}$ adsorbed by modified carbonized straw}

The adsorption kinetics curves of different dosages $(1.2 \mathrm{~g} / \mathrm{L}, 2.4 \mathrm{~g} / \mathrm{L}, 3.6 \mathrm{~g} / \mathrm{L})$ of carbonized wheat straw to $200 \mathrm{ml}$ for $100 \mathrm{mg} / \mathrm{L} \mathrm{Cr}^{6+}$ were shown in Figure 4, and the reaction conditions were as follows: temperature was $25^{\circ} \mathrm{C}$, pH was 9 , oscillation speed was $250 \mathrm{r} / \mathrm{min}$. The results showed that the larger the dosage of adsorbent, the smaller the adsorption capacity at equilibrium, and the time needed to reach adsorption equilibrium was close, which might be related to the concentration of $\mathrm{Cr}^{6+}$. In addition, under different adsorbent dosages, the adsorbent exhibits similar adsorption kinetic behavior, and each curve could be divided into the following three stages: the dosage of $1.2 \mathrm{~g} / \mathrm{L}$ was taken as an example. The slope of the first stage was very large, and the adsorption amount increased from $3.13 \mathrm{mg} / \mathrm{g}$ to $15.21 \mathrm{mg} / \mathrm{g}$ within $1.5 \mathrm{~h}$, which might be caused by the Van der Waals' force between the adsorbent and the adsorbate, indicated that the adsorption process was a fast physical process (Gong, 2011). In the second stage, the adsorption amount increased from $15.21 \mathrm{mg} / \mathrm{g}$ to $16.34 \mathrm{mg} / \mathrm{g}$ within $0.5 \mathrm{~h}$, which was slow. In the third stage, when the adsorption time was longer than $2 \mathrm{~h}$, the adsorption amount reached equilibrium.

The data of Figure 4 were fitted using the first-order kinetic equation, the doubleconstant equation, and the Elovich equation. The fitting results are presented in Figures 5-7 and Table 6.

Table 6. Fitting results of reaction rate equations under different dosages

\begin{tabular}{c|c|c|c|c|c|c|c|c|c}
\hline \multirow{2}{*}{$\mathbf{m}$} & \multicolumn{2}{|c|}{ First-order kinetic equation } & \multicolumn{2}{c|}{ Double-constant equation } & \multicolumn{3}{c}{ Elovich equation } \\
\cline { 2 - 10 }$(\mathbf{g} / \mathbf{L})$ & $\mathbf{k} \mathbf{1}$ & $\mathbf{a}$ & $\mathbf{R}^{\mathbf{2}}$ & $\mathbf{k} \mathbf{2}$ & $\mathbf{a}$ & $\mathbf{R}^{\mathbf{2}}$ & $\mathbf{k} 3$ & $\mathbf{a}$ & $\mathbf{R}^{\mathbf{2}}$ \\
\hline 1.2 & 1.0457 & 4.5353 & 0.868 & 0.4701 & 2.2424 & 0.8732 & 5.4529 & 9.7438 & 0.9192 \\
2.4 & 1.0877 & 4.390 & 0.8642 & 0.915 & 1.2643 & 0.9399 & 3.1211 & 4.4071 & 0.9123 \\
3.6 & 1.0367 & 4.0728 & 0.8608 & 0.7668 & 0.8036 & 0.8946 & 2.2832 & 2.7421 & 0.9277 \\
\hline
\end{tabular}

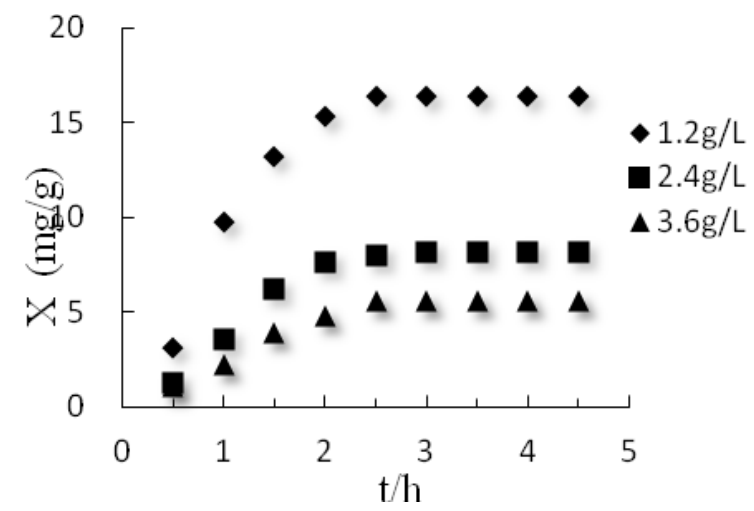

Figure 4. Adsorption kinetic curves of different adsorbent dosages 


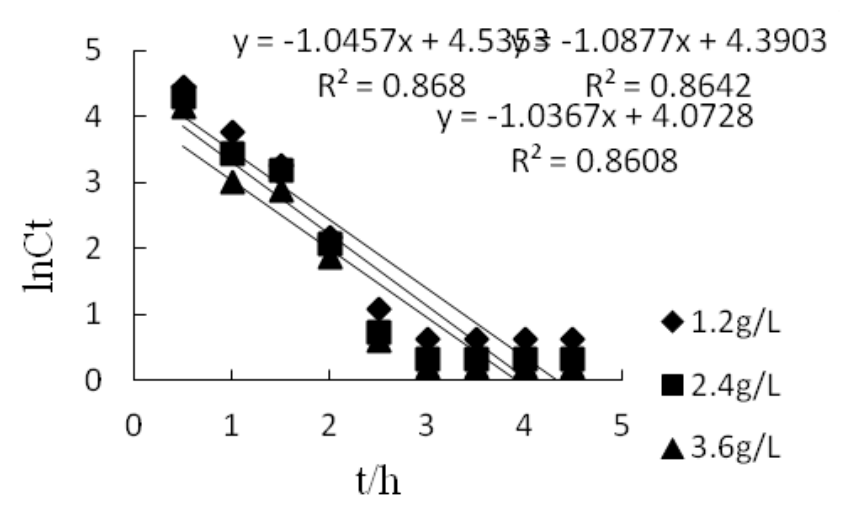

Figure 5. First-order kinetic equation

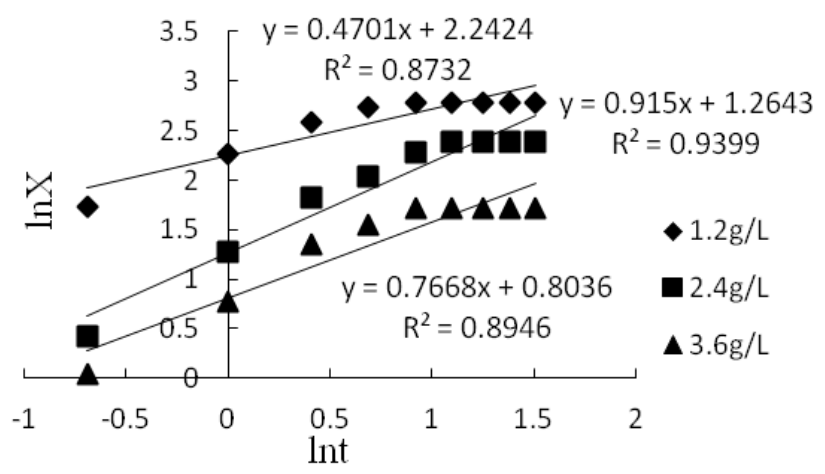

Figure 6. Double-constant equation

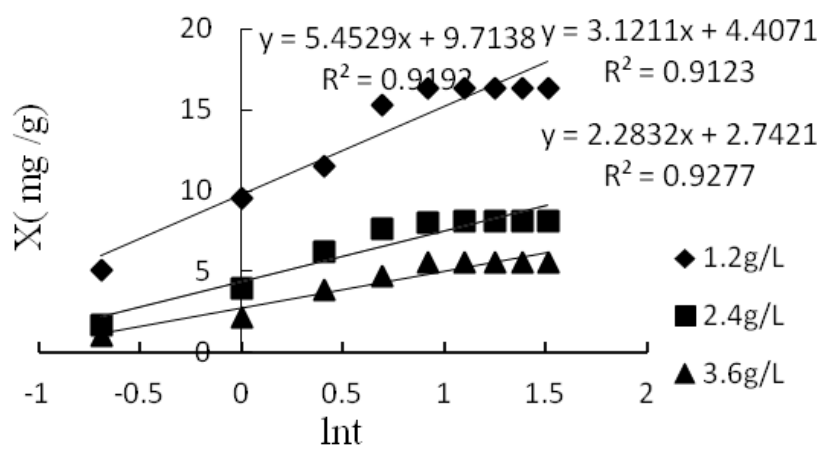

Figure 7. Elovich equation

It could be seen from Table 6 that $\mathrm{R}^{2}$ values of the first-order kinetic equation, the two-constant equation and the Elovich equation increase in turn, and $\mathrm{R}^{2}$ values exceed 0.86. Therefore, the three kinetic equations could better fit the process of adsorbing $\mathrm{Cr}^{6+}$ by modified carbonized straw before the adsorption reaches equilibrium. However, Elovich equation had the highest fitting degree, and its $\mathrm{R}^{2}$ was $>0.91$, which indicated that the fitting effect of Elovich equation was the best, indicated that the fitting range of the first-order kinetic equation could not meet the process of adsorbing $\mathrm{Cr}^{6+}$ by modified carbonized straw. This might be due to the multiple effects of the modified carbonized straw on the adsorption of $\mathrm{Cr}^{6+}$, rather than being limited to the first-order 
kinetic range. In addition, the adsorption process was not a single adsorption mechanism, but a combination of interlayer cation exchange and surface complex adsorption, and it was also related to changes in structure and functional groups after straw modification ( $\mathrm{Li}, 2015)$.

\section{Thermodynamic analysis of $\mathrm{Cr}^{6+}$}

According to the thermodynamic experimental results of adsorption of $\mathrm{Cr}^{6+}$ by modified carbonized straw at different temperatures, the equilibrium partition coefficient $\mathrm{K}$ was obtained. $\operatorname{lnK}$ was used as the ordinate and 1/T was used as the abscissa to get a straight line, as shown in Figure $8 . \Delta \mathrm{S}$ and $\Delta \mathrm{H}$ could be calculated from the intercept and slope of the line respectively, and then $\Delta \mathrm{G}$ was calculated. The calculation results were shown in Table 7.

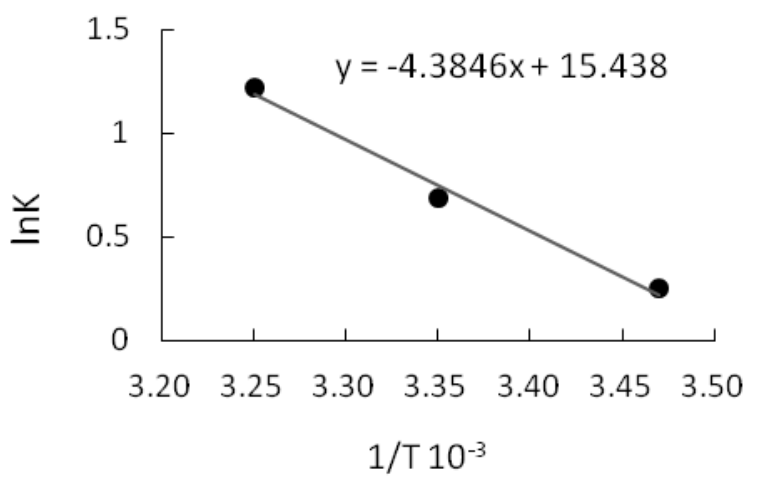

Figure $8 . \ln K-1 /$ T curve

Table 7. Thermodynamic parameters

\begin{tabular}{c|c|c|c}
\hline$\Delta \mathbf{S}(\mathbf{J} / \mathbf{m o l} \cdot \mathbf{k})$ & $\Delta \mathbf{H}(\mathbf{k J} / \mathbf{m o l})$ & $\mathbf{T}(\mathbf{K})$ & $\Delta \mathbf{G ~ ( k J / m o l )}$ \\
\hline \multirow{3}{*}{128.35} & \multirow{3}{*}{36.45} & 288 & $-0.51 \mathrm{~kJ} / \mathrm{mol}$ \\
& & 298 & $-1.80 \mathrm{~kJ} / \mathrm{mol}$ \\
& & 308 & $-3.08 \mathrm{~kJ} / \mathrm{mol}$ \\
\hline
\end{tabular}

It could be seen from Table 7 that $\Delta \mathrm{H}>0$ in the adsorption process, indicated that the reaction process was an endothermic reaction, so the temperature rise was favorable for the adsorption process. $\Delta \mathrm{G}$ could reflect the driving force of a reaction. It could be known from the above data that $\Delta \mathrm{G}<0$ under the temperature conditions of $288 \mathrm{~K}$, $298 \mathrm{~K}$ and $308 \mathrm{~K}$, indicated that the adsorption of $\mathrm{Cr}^{6+}$ by modified carbonized straw was a spontaneous process. Therefore, chromium ions tended to spontaneously adsorb from the liquid body to the surface of the modified carbonized straw, and the spontaneity increased with the increase of temperature. In addition, $\Delta S>0$ indicated that the adsorption of $\mathrm{Cr}^{6+}$ by the modified carbonized straw increased the disorder of the system. According to the adsorption exchange theory, the adsorption of ions in the solution by the adsorbent was a process of entropy reduction. At the same time, the adsorbent would shrink and release part of the water molecules, which would increase the entropy of the system, and the combination of the two would increase the entropy of the system $(\mathrm{Li}, 2013)$. 


\section{Conclusions}

In the experiment, different carbonized straws were modified by different modifiers, and the iodine adsorption value was used as an indicator to compare the adsorption capacity of different modified carbonized straws. It was found that the modified carbonized wheat straw with $2 \mathrm{~mol} / \mathrm{L} \mathrm{FeCl}_{2}$ as modifier had the highest iodine adsorption value $1161.15 \mathrm{mg} / \mathrm{g}$.

Response surface analysis showed that adsorption rate was taken as the response value, temperature, $\mathrm{pH}$ and dosage were taken as the factors, and the quadratic response surface regression model of chromium ion adsorption on modified carbonized straw was obtained. The model was significant, the unfitting term was not significant, and the fitting degree of the equation was high. Therefore, it was feasible to optimize the adsorption conditions of $\mathrm{Cr}^{6+}$ on modified carbonized straw by response surface methodology.

Using wheat straw as raw material, the modified carbonized straw prepared by $\mathrm{FeCl}_{2}$ activation method could effectively absorb chromium ions. The Elovich equation, the double constant equation and the first-order kinetic equation could be well fitted to the process of adsorbing chromium ions by modified carbonized straw. However, Elovich equation had the highest fitting degree, and its $\mathrm{R}^{2}$ was $>0.91$, indicated that the fitting range of the first-order kinetic equation could not meet the process of adsorbing $\mathrm{Cr}^{6+}$ by modified carbonized straw. This might be due to the fact that the main form of adsorption of chromium ions by modified carbonized wheat straw was interlayer cation exchange and surface complex adsorption, rather than a single adsorption mechanism, and it was also related to changes in structure and functional groups after straw modification.

The adsorption of chromium ions by modified wheat straw was a spontaneous endothermic process, and the temperature rise was beneficial to the reaction. Moreover, in the adsorption process, $\Delta \mathrm{S}>0$ indicated that the adsorption of $\mathrm{Cr}^{6+}$ by the modified carbonized straw increased the disorder of the system. This might be due to the change in the surface structure of the modified carbonized straw after the adsorption of chromium ions by the modified carbonized straw, resulting in the increase of the disorder of adsorption system.

The results of this research could raise concerns over possible the comprehensive utilization of agricultural wastes and the treatment of heavy metal wastewater. The authors plan to further study the treatment of different types of heavy metal wastewater by other types of activated carbon under different conditions in the future.

Acknowledgements. This research was financed by the National Natural Science Foundation of China (No. 31600253), the Science and Technology Department Foundation of Sichuan Province (No. 2017JY0087), the Education Department Foundation of Sichuan Province (No. 18ZA0119), the Science and Technology Bureau Foundation of Chengdu (No. 2016-HM01-00004-SF), the Teaching Reform Project Foundation of Chengdu University (CDJGB2017050), the Meat Processing Key Laboratory Foundation of Sichuan Province (No.18-R-17) and the Excellence Project Foundation of Chengdu University (No. 82502\&33111).

\section{REFERENCES}

[1] Cao, Y., Wang, X. Y., Meng, J., Gao, J. P., Lan, Y., Liu, B. (2012): Analysis of current status of straw utilization and its prospect of biocharging. - Crops 4: 9-12. 
[2] Chen, S. H., Yue, Q. Y., Gao, B. Y., Xu, X. (2010): Equilibrium and kinetic adsorption study of the adsorptive removal of $\mathrm{Cr}(\mathrm{VI})$ using modified wheat residue. - Journal of Colloid and Interface Science 349: 256-264.

[3] Chen, W. F., Parette, R., Zou, J. Y., Cannon, F. S., Dempsey, B. A. (2007): Arsenic removal by iron-modified activated carbon. - Water Research 41(9): 1851-1858.

[4] Gong, J. H. (2011): Effect of sulfuric acid modification on adsorption performance of activated carbon. - Fujian Forestry Science and Technology 38(2): 103-106.

[5] Hadjmohammadi, M. R., Kiasari, Z. M., Nazari, S. S. S. J. (2016): Separation of some phenolic acids in micellar liquid chromatography using design of experiment-response surface methodology. - Journal of Analytical Chemistry 71(6): 610-616.

[6] Han, W., Lei, Z. C., Han, R. M., Zhang, Y. Y., Peng, Z. X. (2018): Optimization of phosphorus removal process in actual wastewater treatment plant by response surface methodology. - China Environmental Science 38(8): 2968-2973.

[7] Li, J. H. (2015): Activated modification of wheat straw charcoal and its nitrogen and phosphorus adsorption effects. - PhD Thesis, Chinese Academy of Agricultural Sciences, Beijing, pp. 34-35.

[8] Li, W. H. (2013): Preparation of sludge activated carbon and its adsorption properties for dyes. - PhD Thesis, Shandong University, Shandong, pp. 36-37.

[9] McKay, G. (1984): The adsorption of basic dye onto silica from aqueous solution-solid diffusion model. - Chemical Engineering Science 39(1): 129-138.

[10] Ngah, W. S. W., Hanafiah, M. A. K. M. (2008): Removal of heavy metal ions from wastewater by chemically modified plant wastes as adsorbents: a review. - Bioresourece Technology 99(10): 3935-3948.

[11] Nu, Y. L., Zhao, L. H., Chen, Q., Cao, K. (2017): Adsorption performance of modified corn stover for heavy metal copper ions. - Cleaning World 9: 13-19.

[12] Pang, C. L., Bai, L. J., Liu, L. (2017): Optimization of continuous closed circulating ammonia removal process response surface methodology. - Transactions of the Chinese Society of Agricultural Machinery 48(2): 288-293.

[13] Pinto, P. C., Evtuguin, D. V., Neto, C. P. (2005): Structure of hardwood glucuronoxylans: modification and impact on pulp retention during wood kraft pulpling. - Carbohydrate Polymers 60(4): 489-497.

[14] Shi, R., Li, Y. L. (2014): Preparation of activated carbon from corn stover and its adsorption kinetics. - Journal of Environmental Engineering 8(8): 3428-3432.

[15] Sud, D., Mahajan, G., Kaur, M. P. (2008): Agricultural waste material as potential adsorbent for sequestering heavy metal ions from aqueous solutions - a review. Bioresource Technology 99(14): 6017-6027.

[16] Sun, K., Jiang, J. C. (2009): Research progress and development trend of activated carbon at home and abroad. - Forest Chemical 29(6): 98-103.

[17] Takeshi, K., Yujiro, W., Hirohisa, Y., Takashi, M. (2004): Sorption of phosphates on Alpillared smectites and mica at acidic to neutral pH. - Applied Clay Science 25(3/4): 167177.

[18] Wu, D. (2015): Soybean straw-based porous carbon material and its $\mathrm{CO}_{2} / \mathrm{CH}_{4}$ selective separation characteristics. - PhD Thesis, Fujian Normal University, Fujian, pp. 25-27.

[19] Xiao, G., Liu, J. C., Jin, B. S., Zuo, W., Wang, Q.(2010): Study on characteristics of high temperature carbonized coke in rice straw. - Journal of Combustion Science and Technology 16(1): 1-4.

[20] Zeng, Y. G. (2014): Research on absorbing heavy metal ions of landfill leachate by PAMPS. - Advanced Materials Research 955-959: 2192-2195.

[21] Zeng, Y. G., Li, L. (2014): Study on treatment of heavy metal ions of chemical wastewater by ion exchange resin. - Advanced Materials Research 955-959: 2230-2233.

[22] Zeng, Y. G., Li, W. Y., Wang, L. L., Du, T. T., Huang, J., Huang, Z. W., Wang, J., Tang, J. L., Wang, M. K., Wang, J. M., Jiang, C. Y., Yang, P. (2018): Study on the kinetics of 
the adsorption of reactive brilliant red K-2BP onto modified soybean straw activated carbon. - Desalination and Water Treatment 125: 302-309.

[23] Zhao, Y. (2016): Harm of heavy metal wastewater pollution. - Jiangxi Chemical 3: 145146.

[24] Zhong, Q. Q. (2011): Preparation of wheat chelating chelate sorbent and its adsorption properties for $\mathrm{Cu}(\mathrm{II})$ and $\mathrm{Cr}(\mathrm{VI})$. - PhD Thesis, Shandong University, Jinan.

[25] Zhu, J. L., He, X. F., Wang, Z. W., Li, Z. F., Lei, T. Y. (2010): Experimental study on pyrolysis of corn straw granules for carbon production. - Acta Energiae Solaris Sinica 31(7): 789-793.

[26] Zhu, Q. Q., Zhou. H. L. (2014): Structural changes of cellulose during carbonization and activation. - Journal of University of Science and Technology Beijing 36(11): 15451551. 